\title{
Emergency remote teaching in linguistics during the early COVID-19 pandemic
}

\author{
Reed Blaylock, Evan D. Bradley, Ann Bunger \& Taylor Sharp*
}

\begin{abstract}
In the spring of 2020, the COVID-19 pandemic forced many higher education institutions to transition suddenly to emergency remote teaching. This paper describes the results of a survey that the Linguistic Society of America carried out on the response to this situation among teachers and learners in the linguistics community. We consider what teachers tried, what students found helpful, and what got overlooked.
\end{abstract}

Keywords. emergency remote teaching; linguistics; pandemic; remote learning

1. Introduction. In the spring of 2020, the COVID-19 pandemic caused many higher education institutions around the world to transition to remote learning. This transition was cross-disciplinary, rapid, and global (Cuschieri \& Agius 2020, Czerniewicz et al. 2020, de Souza et al. 2020, García-Peñalvo et al. 2020, Gillis \& Krull 2020, Osman 2020, Rotas \& Cahapay 2020, Shim \& Lee 2020, Wise \& Bergner 2020, Huang, Shi \& Yang 2021, Jelińska \& Paradowski 2021, Moorehouse \& Kohnke 2021, Smith \& Kaya 2021, etc.).

The emergency remote teaching (ERT) that emerged during this period is distinct from carefully-designed online learning experiences (Hodges et al. 2020). As the pandemic disrupted our lives, the shift to ERT necessitated the rapid and creative development of temporary new structures and routines amid a time of uncertainty (Milman 2020). In some cases, instructors were expected to shift their courses online overnight, without adequate training in this new modality or resources to support it. Some instructional choices were made with scholarly teaching practices in mind, but just as often teachers and learners were in reactive mode: scrambling to acquire new skills and to find new ways to achieve learning outcomes. The experience was challenging, and it highlighted inequities across institutions, instructors, and learners (Czerniewicz et al. 2020; de Souza et al. 2020; Gillis \& Krull 2020; Rotas \& Cahapay 2020).

Within the linguistics community, this situation directed a spotlight on teaching and learning, and in late May 2020, the Linguistic Society of America (LSA) distributed a survey that asked respondents to reflect on institutional responses and teacher and learner experiences during this period. In this paper, we describe the results of that survey, with particular focus on how teachers adapted their courses for ERT and how learners responded to those changes. Overall, teachers reported that they made a wide array of changes to their courses midstream, including content, delivery modes, and synchronicity. Learners reported that flexibility in terms of both course content delivery and instructor accommodations were especially important in helping them manage this transition, as well as the ability to make individualized lifestyle adjustments. In the Discussion we consider what might have been overlooked in many ERT situations, most notably, attention to justice, equity, diversity and inclusion (JEDI).

\footnotetext{
* This survey was designed in conjunction with the Linguistic Society of America's Faculty Learning Community on Scholarly Teaching. This group and the authors of this paper represent a variety of teaching and learning roles. Authors (listed in alphabetical order): Reed Blaylock, graduate student, University of Southern California (reed.blaylock@gmail.com); Evan D. Bradley, Associate Professor, Pennsylvania State University, Brandywine (evan.d.bradley@psu.edu); Ann Bunger, Senior Lecturer, Indiana University (acbunger@indiana.edu); Taylor Sharp, undergraduate student, Boise State University (taylorsharp@u.boisestate.edu).
} 
2. Survey design. This research was carried out with the approval of the University of MichiganFlint Institutional Review Board.

2.1. Methodology. To collect information about ERT experiences among the linguistics community during Spring 2020, we created a mixed-methods survey in Qualtrics. All survey participants were presented with multiple-choice and short-answer questions about demographic information and the term during which the transition to ERT occurred. Participants who reported that they were teaching during that term were presented with open-ended questions about changes they made to a course they were teaching. Participants who reported that they were taking classes during that term (including, optionally, those who also reported that they were teaching) were presented with open-ended questions about their experience as learners.

Open-ended questions for teachers:

- Think about your original plans for this class. What changes did you make to the course, and how did you decide what to do? (Consider, for example, synchronicity of class meetings, course content, and assessment.)

- If you created accessible content (e.g., closed captioning for videos, image tags), what kinds of accommodations did you make? Will your decisions about accommodations for accessibility affect your future classes?

- How did the remote portion of your class go? What went well? What was challenging?

- If you made any particular innovations that you would like to share, tell us about them.

Open-ended questions for learners:

- What changes did your instructor make to the course? (Consider, for example, synchronicity of class meetings, course content, and assessment.)

- Please describe one specific thing that your instructor did that was particularly helpful for your learning.

- How did you adjust your learning strategies to deal with the transition to remote learning? (Consider, for example, how you managed your schedule, where and when you studied, and how you approached assignments.)

- What resources were most useful in helping you succeed in this course and why? (For example, material posted by your instructor, material you found on your own, office hours, study groups, etc.)

The survey opened on May 21, 2020 and closed on June 11, 2020. Participants were recruited by sending a link out to LSA members and through social media. Members were encouraged to share the link with their colleagues and students.

2.2. PARTICIPANTS. A total of 442 individuals responded to the survey, $99 \%$ of whom reported an affiliation with 4 -year colleges and universities (68.6\% public; $19.9 \%$ private; $0.5 \%$ tribal colleges; $11.1 \%$ unspecified). Of these, $54 \%$ of our respondents $(n=238)$ identified themselves as faculty, $17 \%$ as graduate students $(n=74)$, and $26 \%$ as undergraduate students $(n=117) ; 3 \%$ did not fit cleanly into these categories $(n=13$; e.g., postdoctoral fellows, high school teachers, and journal editors). Survey respondents came from 44 U.S. states $(80 \% ; n=354)$ and 6 Canadian provinces $(4 \%, n=16)$ as well as from outside these countries $(15 \%, n=68$; an additional 4 participants did not specify their geographic location).

About half of the faculty members who responded to the survey (55\%) were tenured (Full, Associate) professors. One quarter (25\%) were tenure-track Assistant Professors; $18 \%$ were non- 
tenure-track or contingent faculty (Lecturers, Adjuncts, or Visiting); $2 \%$ held a non-university faculty position (e.g., high school teachers). These linguists were employed in a wide variety of departments, including Linguistics, English, various languages, Education, Communication Sciences, Cognitive Sciences, Philosophy, Anthropology, Business, Communication, International Studies, Ethnic Studies, Humanities, Liberal Studies, or Social Sciences. Overall, 96\% of faculty respondents were teaching during Spring 2020.

Graduate students who responded to the survey were overwhelmingly (89\%) in $\mathrm{Ph} . \mathrm{D}$. programs; $8 \%$ were in Masters programs; and 3\% did not specify their program. Most (70\%) of these graduate students were teaching in the spring; most $62 \%$ were enrolled in courses; and many $(38 \%)$ were doing both. A minority of graduate student respondents $(5 \%)$ were neither teaching nor enrolled in courses (e.g., working on research or writing their dissertations).

Most of the undergraduate students who responded to the survey were linguistics majors $(72 \%)$ or minors $(9 \%)$. They came from a range of levels: $9 \%$ were first-year students; $21 \%$ were sophomores; 28\% were juniors; and 42\% were seniors (or higher). Almost all (99\%) of these undergraduate students were enrolled in courses in Spring 2020, and several (6\%) were also serving a teaching role during that period.

Additional information about participant demographics is given in Sections 4 and 5.

2.3. ANALYSIS. In the following sections, we describe findings from the survey related to institutional expectations and support during the transition (Section 3) and the experiences of teachers (Section 4) and learners (Section 5). ${ }^{1}$

We used an inductive approach (Saldana, 2016) to assess responses to open-ended questions. In the first coding cycle, we applied values coding and descriptive coding methods to identify attitudes and themes in responses. One pair of coders completed independent codes of all responses to the teacher open-ended question; another pair worked through the learner openended questions. Intercoder reliability for first-cycle coding averaged 95\% across questions; any disagreements were adjudicated by a third coder. One of the initial coders for each set of questions then carried out a process of focused coding to refine and categorize first-cycle codes.

3. Transition situation. This survey captures information about courses offered in Spring 2020 semesters $(81 \%)$ and quarters (19\%). Across these term types, 91\% of the courses that respondents described were originally scheduled to meet in person, and $98 \%$ of them were remote after the transition.

During this time, both teachers and learners were juggling extra work and personal responsibilities. Some of these responsibilities included:

- extra administrative work and emotional labor,

- extra time spent creating new course materials and learning about new technologies for remote teaching and learning,

- time spent adjusting personal strategies for mental health and monitoring children taking online courses, and

- time devoted to using linguistic tools to support the community by making sure multilingual students had information about the pandemic and the campus response to it in their preferred languages.

\footnotetext{
${ }^{1}$ Although we looked in our dataset for inequities based on race, gender, or the precariousness of faculty employment status, because of our survey design and the population who responded to it, we didn't find anything that stood out from the general noise of a largely qualitative dataset.
} 
The nature of the support that institutions offered varied, but there were some general trends. Time was the least flexible commodity: less than half of the respondents (43\%) were given extra time by their institutions to make the transition - this most often took the form of an extended Spring Break. Some institutions offered technology to assist teachers (58\% of all respondents) and students ( $63 \%$ of all respondents). Some institutions offered financial assistance for students (55\% of all respondents). Finally, most institutions were able to offer flexibility in curricular policies: for example, either requiring or allowing students to take courses pass/fail $(92 \%$ of learners) or to withdraw from courses without penalty (77\% of learners).

4. Teachers. Section 4.1 summarizes the demographic information reported by the teachers who took the survey. The following subsections summarize the most frequent responses to openended questions (listed in section 2.1) about changes that teachers made to their courses (section 4.2), what kinds of accessibility accommodations they did or did not make (section 4.3), and their attitude toward teaching during the pandemic (section 4.4). ${ }^{2}$ The most frequent Responses in each subsection are broken down by whether the course being referred to was an undergraduate introductory course, an advanced undergraduate course, or a graduate course.

4.1. TEACHER DEMOGRAPHICS. There were 295 survey respondents teaching during Spring 2020: 228 of those were faculty, 52 were graduate students, 7 were undergraduate students, and 8 were postdocs or another kind of teacher. Most (58\%) of the teachers were responsible for more than one course, and only about a third (28\%) had any experience whatsoever with online classes (i.e., as either teacher or learner). Most teachers were therefore in an unfamiliar situation, and most had primary responsibility for deciding how to adapt their courses for ERT.

The scope of this section will be restricted to faculty respondents. Of these, $75 \%$ identified as White, $10 \%$ were Asian, $6 \%$ were Latinx, $1 \%$ were Black, $<1 \%$ were multi-racial, and $7 \%$ did not specify their racial/ethnic identity. Of the same respondents, $46 \%$ identified as female, $32 \%$ as male, and $3 \%$ as non-binary; $19 \%$ of these respondents did not report their gender.

\subsection{COURSE CHANGES.}

Think about your original plans for this class. What changes did you make to the course, and how did you decide what to do? (Consider, for example, synchronicity of class meetings, course content, and assessment.)

The question about changes that teachers made to their courses was answered by 156 faculty respondents: 76 (49\%) teachers of introductory undergraduate courses, 54 (34\%) teachers of advanced undergraduate courses, and $26(17 \%)$ teachers of graduate-level courses. The most common response to this question was related to synchronicity - specifically, the choice of whether to teach courses synchronously, asynchronously, or with a blend of synchronous and asynchronous components. Figure 1 shows the percentages of teachers who were doing ERT using each of these synchronicity styles, broken down by the level of the course being taught. In this chart, the bars for each type of course (e.g., all the "Intro" bars) add to 100\% (but this will not be true for subsequent charts).

Faculty teaching introductory courses reported the most asynchronicity, with many (36\%) courses completely asynchronous and some (25\%) courses blending synchronous and asynchronous learning. Teachers of both graduate and advanced undergraduate courses reported using

\footnotetext{
${ }^{2}$ Answers to the question about teaching innovations in section 2.1 were incorporated in a database of tools. See section 6.2 for a link.
} 
synchronous methods more often than teachers of introductory courses $(27 \%$ and $32 \%$ vs. $20 \%$, respectively); but while a quarter (26\%) of teachers of advanced undergraduate courses reported using a blend of synchronous and asynchronous learning, teachers of graduate courses rarely reported blended synchronicity types (12\%). Teachers of graduate courses were also most likely to not report making any changes in synchronicity (42\%).

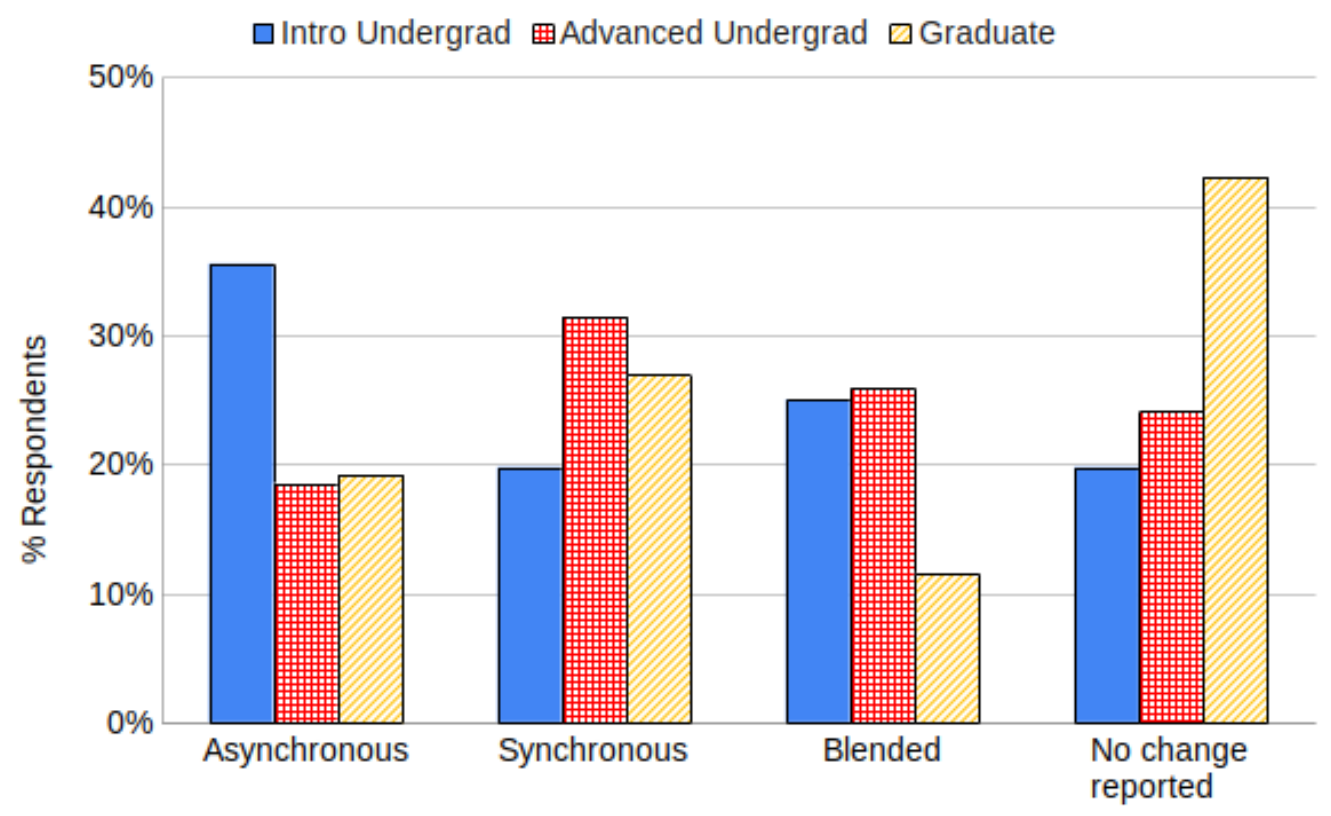

Figure 1. Teacher reports of changes to course synchronicity in response to the question "What changes did you make to the course?"

In addition to reporting on the synchronicity of their classes, respondents reported a wide variety of changes to their courses, including altering course requirements, creating new videos or finding existing videos for asynchronous learning, adjusting office hours formats, reducing the number or duration of synchronous meetings, adopting different strategies for class engagement, altering, swapping, or eliminating assessments, adding extra credit, making the course pass/fail, making assessments or exams optional, using more frequent low-stakes assessments, grading more leniently, making tests open book, changing the content of the course, and being more flexible with deadlines. Some of the more common responses are shown in Figure 2. The following quote from a teacher of an introductory undergraduate course demonstrates the multitude of changes some teachers made all at once:

I decided to make the lectures asynchronous, the TA section meetings synchronous, and to add weekly optional synchronous meetings with me as instructor. I had to shorten the syllabus by a week, cancelled the remaining quiz and final exam, and lightened the writing assignments. My institution switched all grades to Pass/No Record.

The most common type of change teachers made to their courses was to assessments: e.g., swapping out assessments for completely different assessments, getting rid of final exams, or moving to low stakes assessments. Respondents also chose to make some fundamental changes to the structure of their courses, including included reducing lecture time, reducing the number of class meetings, and reducing the number of assessments. Some teachers reported making new 
videos of themselves in an asynchronous format; this was most common among teachers of introductory courses ( $40 \%$ of intro teachers vs $20 \%$ of advanced undergrad teachers and $8 \%$ of graduate teachers). About one fifth of teachers of undergraduate classes ( $20 \%$ introductory undergraduate; $21 \%$ advanced undergraduate) and a slightly lower percentage (15\%) of teachers of graduate courses also reported adopting flexible policies with respect to deadlines or grading.

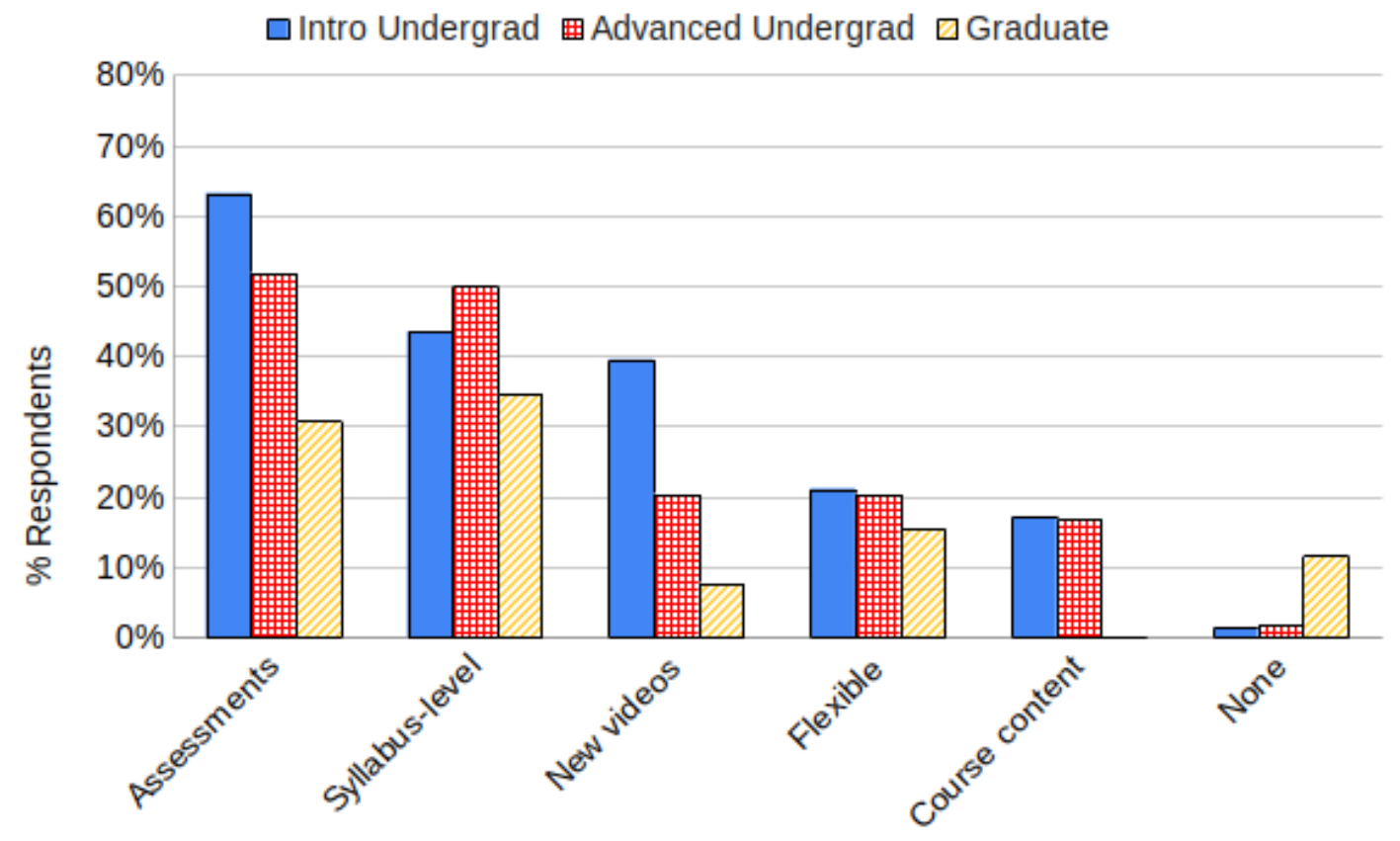

Figure 2. Frequent categories of responses from teachers to the question "What changes did you make to the course?"

Overall, teachers of undergraduate courses reported making the most changes to their courses. Teachers of graduate-level courses were the least likely to report making changes in many of our categories, and were most likely to report making no changes at all.

\subsection{ACCESSIBILITY.}

If you created accessible content (e.g., closed captioning for videos, image tags), what kinds of accommodations did you make? Will your decisions about accommodations for accessibility affect your future classes?

There were 60 fewer respondents to this question then to those summarized in section 4.2 and 4.4. Of the 96 respondents to this question, 42 (44\%) were teaching introductory undergraduate courses, 37 (38\%) were teaching advanced undergraduate courses, and $17(18 \%)$ were teaching graduate-level courses. Overall, teachers did not seem to make accommodations for accessibility as part of their shift (Figure 3). The most common responses to this question were "none" or "N/A" (grouped here as "None"), suggesting that teachers did not make accessibility changes unless they had to. (Given that so many teachers chose not to respond to this question at all, it seems reasonable to infer that the percentage of teachers who made no changes is even higher than reported here.) The teachers who did make accessibility changes most often reported on the captions and transcripts that they created for videos or other material they were using. A 
few teachers reported having already taken accessibility into consideration or having it required by their institutions.

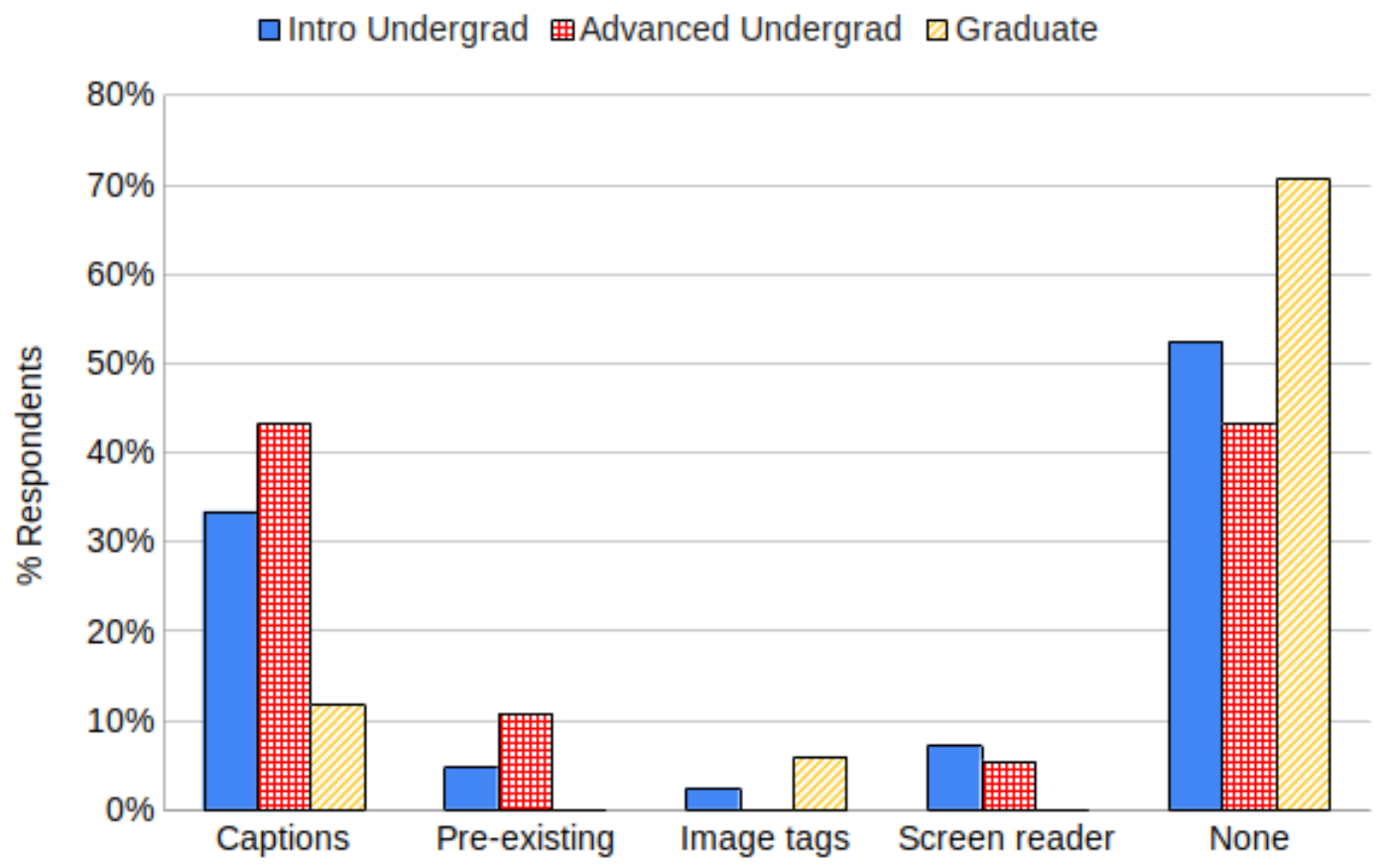

Figure 3. Frequent categories of responses from teachers to the question "What kinds of accommodations did you make?"

Teachers of graduate-level courses were least likely to use captions or to report making accommodations and most likely to report making no accommodations. This may be partly related to the amount of changes that were made in their courses overall, since teachers of graduate-level courses were also less likely to use asynchronous material, they were not making as many videos that needed captions.

\subsection{MoOD.}

How did the remote portion of your class go? What went well? What was challenging?

There were 156 respondents to this question: 75 (48\%) teachers of introductory undergraduate courses, $53(34 \%)$ teachers of advanced undergraduate courses, and $28(18 \%)$ teachers of graduate-level courses. We started by assessing general mood (Figure 4) as Positive (they had only positive things to say about teaching at the start of the pandemic), Negative (they had only negative things to say), Mixed (they said at least one positive and at least one negative thing), or Neutral (responses usually started with a statement like "It was OK"). The most common attitude toward these ERT terms was Mixed, followed in percentage by Negative responses. Moods were relatively consistent across faculty teaching all levels of courses. Faculty teaching advanced undergraduate courses were least likely to report overall negativity $(23 \%)$, and faculty teaching graduate courses were most likely to report negativity $(36 \%)$. 


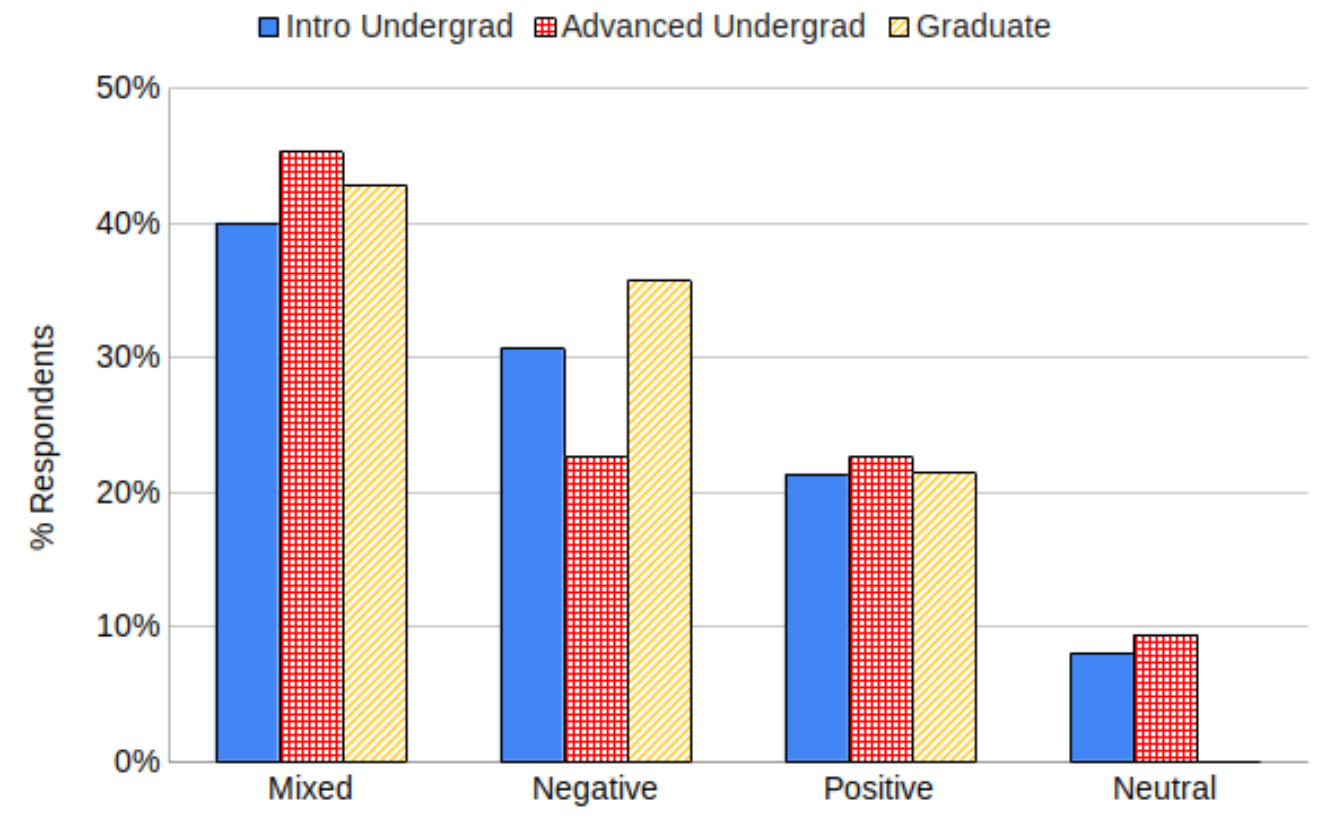

Figure 4. Moods represented in responses from teachers to the question "How did the remote portion of your class go?"

We also coded teachers' feelings about the term into specific categories (Figure 5). The most prominent issues on teachers' minds were remote technology, engaging with students, and the teachers' overall workload.

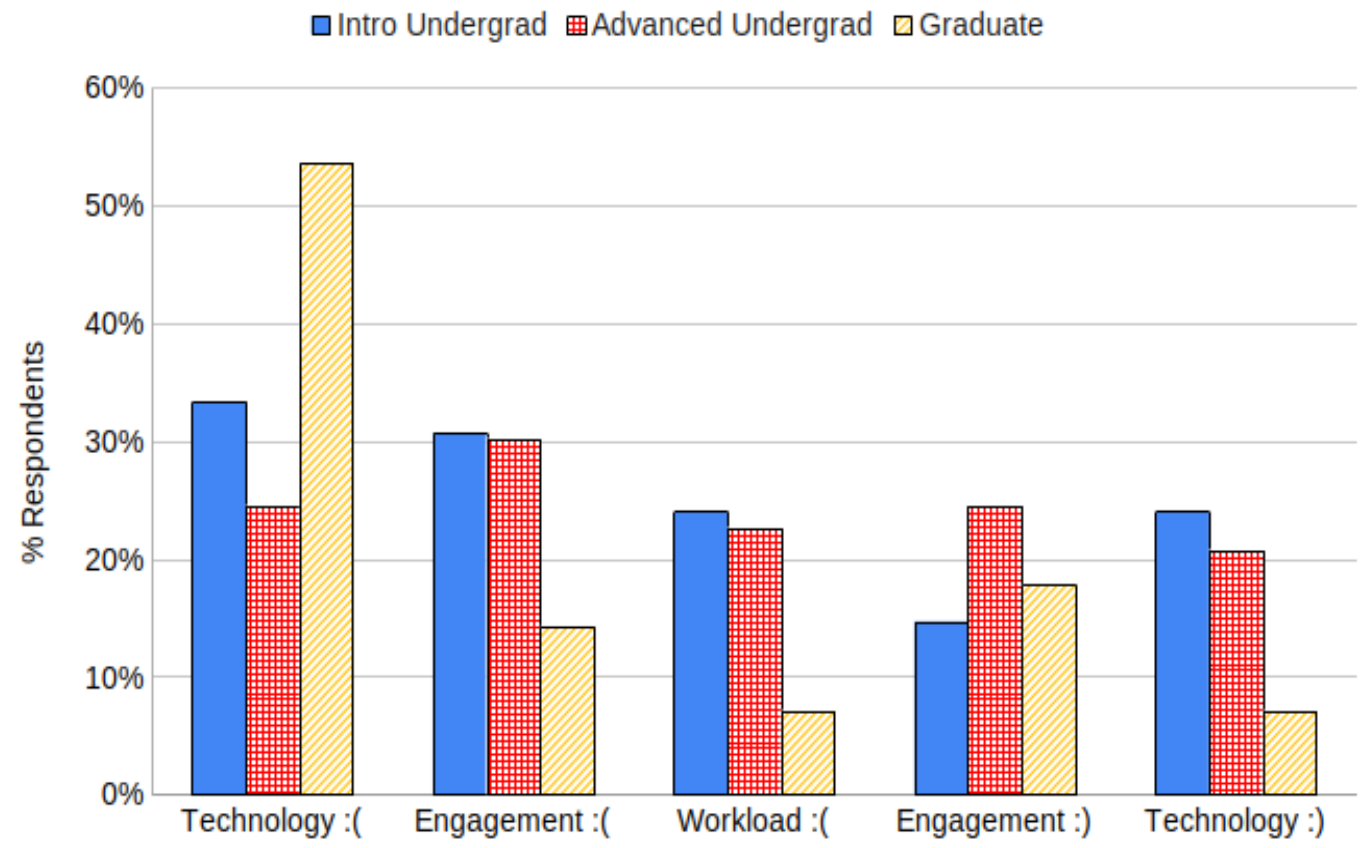

Figure 5. Frequent categories of responses from teachers to the question "How did the remote portion of your class go?" categorized by what they thought went well $[:)]$ and what went poorly $[:(]$. 
These categories were most often brought up in negative terms, but some teachers also reported having positive experiences with engagement and technology. In some cases, teachers started ERT feeling uncomfortable with the new situation but found advantages as time went on. The response below from a teacher of a graduate class illustrates the common negative feeling that student engagement suffered because instructors found it difficult to assess how much students were following along with class:

It went fairly well. Took a bit to get used to giving synchronous lectures with slides over Zoom. I usually improvise more in the classroom. What's challenging is the reduced and constrained amount of non-verbal communication and feedback. So much of classroom interaction involves mind-reading and that is much harder when communication channels are going through an electronic bottleneck.

On the more positive side, some instructors found they had student engagement that was as good or better than what they usually get in face-to-face classes. From one teacher of an advanced undergraduate class:

Online discussion forums as an alternative to in-class discussion went surprisingly well - students truly interacted with each other and the topics and some wrote more often than what was required. Challenges included keeping up communication with students to help them stay on track and having to determine grades when I knew students were struggling with focus (my institution didn't decide to go with Pass/Fail for all students).

Faculty teaching graduate-level courses were most likely to feel negatively about technology (54\% vs $33 \%$ of teachers of introductory courses and $25 \%$ of teachers of advanced undergraduate courses) despite reporting the least amount of work making videos and accessible content. Overall, faculty teaching graduate-level courses were least likely to feel negatively about student engagement (14\%), which may be related to the lower likelihood among this group of holding classes asynchronously. Additionally, the same group of teachers was least likely to respond negatively about overall workload (7\%), presumably because they were also least likely to report making any changes to their classes. Conversely, teachers of undergraduate courses were much more likely to respond negatively about overall workload (24\% and $23 \%$ of teachers of introductory and advanced undergraduate courses, respectively), pointing specifically to the added emotional labor and time to prepare course materials involved in ERT. While teachers of all course types were most often able to find silver linings or acknowledge that the situation improved over time (the Mixed category of Figure 4), almost no one said anything positive about the extra work imposed by the transition to ERT.

4.5. TEACHER SUMMARY. Teachers adopted a variety of approaches and attitudes to ERT. In general, they seemed to be most concerned with the logistics of getting their courses up and running in remote formats. Teachers' opinions about how their approaches to ERT went were similarly varied: while almost no one enjoyed the extra labor (including emotional labor) in the transition to ERT, teachers' opinions about the results of this burden ranged from strongly negative to surprisingly positive. Of all the choices made during this shift, teachers were most consistent in not reporting making any accessibility accommodations.

5. Learners. We asked respondents who were taking classes during this time about how they experienced the transition, both in terms of the changes their teachers made to their courses and how they adapted their learning to match these changes. 
5.1. LEARNER DEMOGRAPHICS. Of our survey respondents, 164 were enrolled in courses during Spring 2020. Of these, 2 were faculty, 46 were graduate students, and 116 were undergraduate students. The scope of this section will be restricted to student respondents. Most learners (85\%) were enrolled full time (in at least three courses), and only 7\% reported dropping any courses as a result of the transition. About half (51\%) of learners had previously taken an online course. The learner respondents predominantly reported their racial/ethnic identity as White (73.9\%), with $11.1 \%$ reporting as Asian, $9.2 \%$ as Latinx, $5.2 \%$ as Black, and $<1 \%$ as other races. Half $(50 \%)$ of student respondents were women, $29 \%$ were men, $8 \%$ were nonbinary, and $13 \%$ did not report their gender.

The following subsections summarize the most frequent responses to the second and third open-ended questions ${ }^{3}$ we asked learners, broken down by whether the course being referred to was an undergraduate introductory course, an advanced undergraduate course, or a graduatelevel course. We did not conduct an in-depth analysis of learner responses about changes made to the course because we asked a similar question of instructors, who provided more detail about syllabus-level and other course changes which may have been less apparent to students.

\subsection{TEACHER ACTIONS.}

Please describe one specific thing that your instructor did that was particularly helpful for your learning.

The actions taken by their teachers that students most commonly reported as being helpful for their learning were extensions to deadlines for course assignments (Figure 6). Undergraduate students, but not graduate students, also reported that video recordings provided by the instructor were helpful. Both groups reported that maintaining course synchronicity was helpful. Undergraduate students also appreciated additional resources or course materials provided by teachers.

Instructor flexibility, in a general sense, was also reported as helpful by learners. This exam-

ple from an advanced undergraduate student's response illustrates that many learners appreciated flexibility due to the added complexity and stress of the transition:

Honestly, I really struggle to learn in the environment I'm in, and I can't focus in online classes at all. The best thing [teacher] did for me was make attendance optional and tell me specifically that he could work with me if I needed extensions or anything so that I could maintain my mental health enough to get out of this without losing grip on all of my classes.

\footnotetext{
${ }^{3}$ Answers to the question about helpful resources in section 2.1 were incorporated in a database of tools. See section 6.2 for a link.
} 


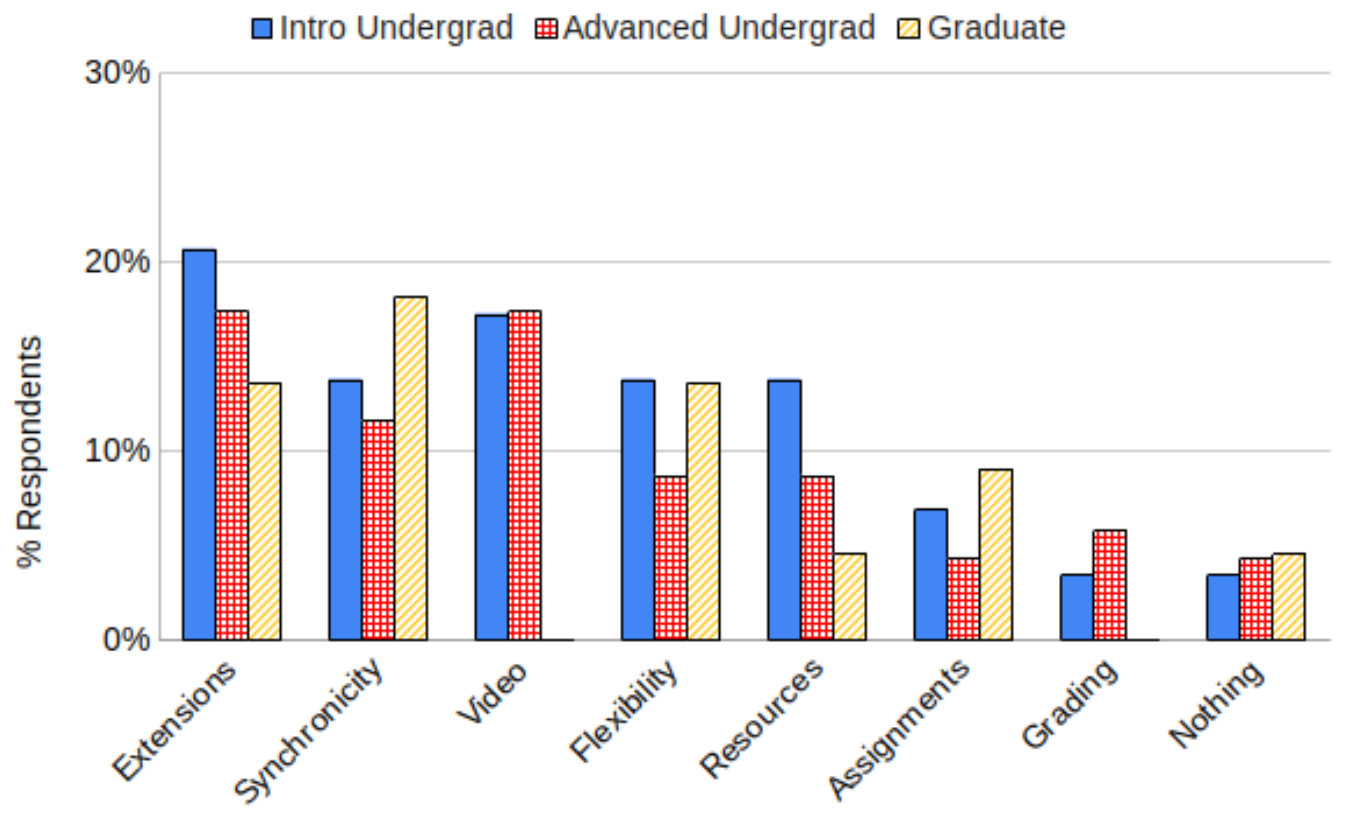

Figure 6. Frequent categories of responses by students to the question "What did your instructor do that was helpful?"

\subsection{LEARNER ADAPTATIONS.}

How did you adjust your learning strategies to deal with the transition to remote learning? (Consider, for example, how you managed your schedule, where and when you studied, and how you approached assignments.)

In this question, we asked students what changes they made to their learning strategies in response to the transition (Figure 7 ). More than one-third (37\% overall) of the respondents reported that they created a space to study or attend class at home, presumably because they could no longer access campus resources. The most commonly reported strategy reported by undergraduates was maintaining a regular schedule for studying and completing classwork. One student reported how these strategies helped them stay focused on learning:

I only sat at my desk during class rather than on my couch or bed and tried to keep to my normal schedule as much as possible.

Graduate students were less likely than undergraduate students to report that creating a study schedule was helpful during the transition, although this could be because graduate students were already more likely to have a regular schedule prior to the transition. Graduate students were also more likely than undergraduates to report that they made no changes to their learning strategies during the transition. One fifth $(20 \%)$ of learners reported that they had to consider the priority of their schoolwork relative to other commitments (e.g., work, family care). 


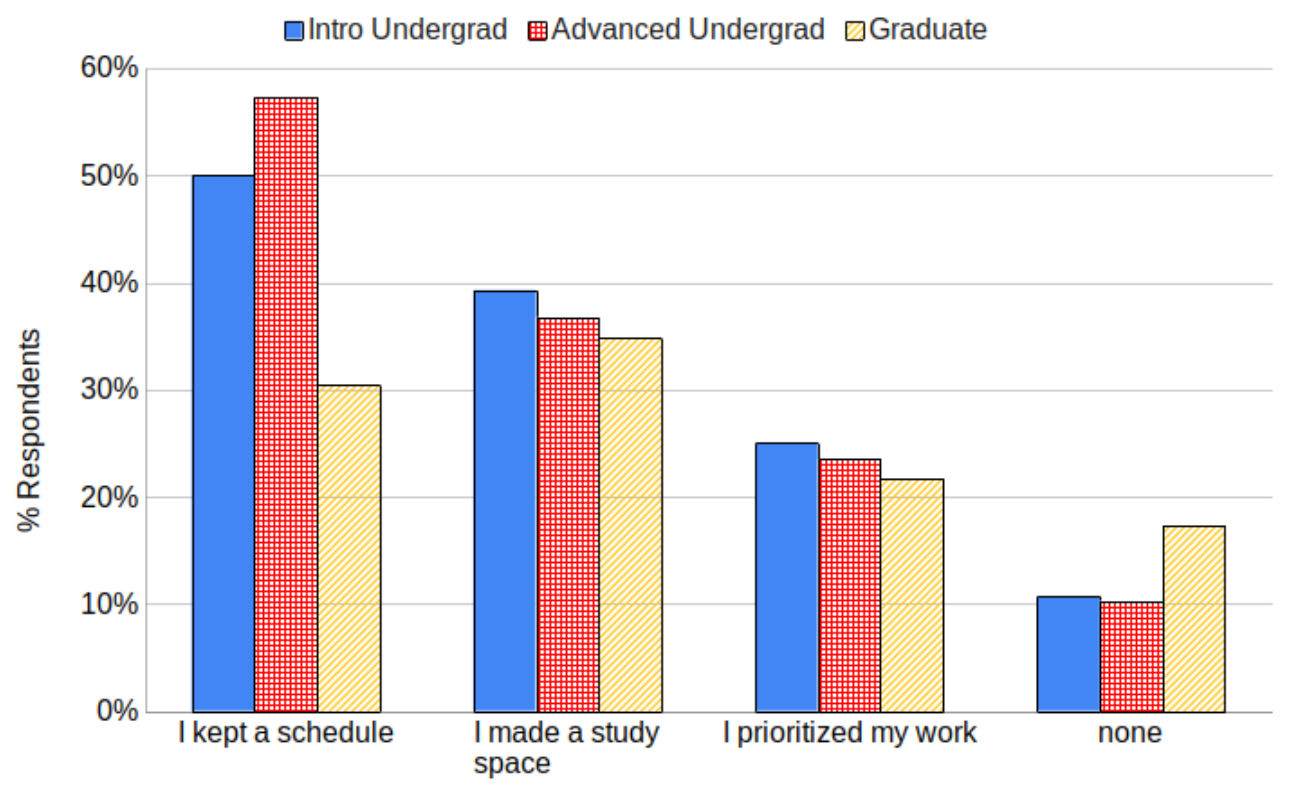

Figure 7. Frequent categories of responses from students to the question "How did you adjust your learning strategies?"

5.4. LEARNER SUMMARY. Overall, the most significant factors identified by learners, both in terms of their own learning strategy and the accommodations made by their teachers, were those related to flexibility or time management, including recorded classes and extension of assignment due dates. They also valued the ability to maintain a synchronous connection with the class.

6. Discussion. In section 6.1, we present our comments on the survey results, in particular emphasizing the benefits of integrating flexibility into course design and the need for stronger graduate-level pedagogy. In section 6.2, we focus on gaps we identified in survey questions and answers - particularly the lack of emphasis on justice, equity, diversity, and inclusion - and how to take them into consideration post-pandemic.

It is important to keep in mind that this report focused on experiences with emergency remote teaching. These findings may not extend to the experience of online teaching and learning in general, or even necessarily to well-informed but still reluctant remote teaching and learning. For example, many teachers were advised to move to asynchronous teaching styles to more flexibly accommodate learners who would not be able to attend synchronous classes (e.g., because they were now in different time zones or had home matters to deal with during class time), but while that strategy may be suitable for courses designed to be taken online, synchronicity was one of the top things learners in this survey reported valuing in their classes.

Moreover, our interpretation of survey responses is necessarily limited by the wording of some of the questions, as respondents may have been more likely to talk about the suggested topics than about other aspects of their experience during this period.

6.1. TEACHING \& LEARNING INTEGRATION: WHAT DID WE LEARN? Learners highly valued flexibility and extensions related to assignments and deadlines. In turn, many teachers chose to reduce the number of assignments in their course, made assignments optional, or were more flexible with deadlines. But even in the absence of a pandemic, students still have emergencies and life events that interrupt their education. Pedagogical frameworks with flexibility at their core including humanizing pedagogy (Karayaka 2021) and skills-based grading (Tomlinson \& McTighe 
2006, Zuraw et al. 2019) can help instructors accommodate students' need for flexibility in the return to in-person teaching.

After flexibility with deadlines, the two course changes that learners most often mentioned as being helpful were the use of video and a synchronous modality. We interpret this dichotomy as learners appreciating flexibility in teaching style: synchronous classes felt the most similar to familiar in-person classes and provided opportunities to engage with the teacher and other classmates, while asynchronous materials gave learners more opportunities to learn at their own pace and to revisit course content when desired.

Whether or not a course is taught face-to-face, instructors can keep both of these student preferences in mind during course design. One strategy might be to use a flipped classroom approach (Bergmann \& Sams, 2012), in which information that might often be found in a lecture is taught through shorter lecture videos or readings that learners view asynchronously, and the exercises and assessments students would usually perform on their own as homework become classwork they do with the guidance of the teacher, either on their own or with other students. The flipped classroom model can satisfy learners' desires for both classroom community during synchronous meetings and self-paced individual learning outside of class. Ideally, institutions would support teaching models like these by providing technical and pedagogical training for implementing these models, and by recognizing the additional time required for instructors to implement and maintain such a course design. Teachers and learners can also make use of instructional technologies to extend the community outside the classroom, for example, using discussion boards in a learning management system to facilitate remote interaction related to asynchronous course materials.

Finally, we return to the observation that teachers of graduate-level courses did relatively little to shift their courses compared to the teachers of undergraduate courses. Teachers of graduate courses were both the most likely to report making no effort to create accessible courses in the shift to ERT and the least likely to report making any changes to their courses at all. This may reflect an assumption that graduate students have sufficiently greater autonomy and academic competence than undergraduate students, and therefore that they do not require much pedagogical attention. At best, that assumption and the lack of effort for graduate courses is an oversight that can be remedied with thoughtful pedagogical practices (e.g., Rosenthal 2005) - after all, graduate students are still students. At worst, the dearth of attention paid to graduate-level courses indicates that some instructors and institutions have little interest in preparing graduate students for their future in (or more likely, out of) academia; it may also contribute to the mental health crisis affecting many graduate students - a crisis that was exacerbated by the COVID-19 pandemic (Chirikov et al. 2020) and that will continue until learning, working, and living conditions for graduate students are improved.

\subsection{ACTIONABLE GAPS.}

6.2.1. JEDI. Notably absent from most survey responses was a consideration of justice, equity, diversity, or inclusion (JEDI). For example, only a handful of teachers expressed awareness of the ramifications of the pandemic that disproportionately affected disadvantaged students (Soria $\&$ Horgos 2020). This may be due in part to there not being a survey question that addressed these topics specifically. However, given the responses to the question we asked teachers about making accessibility changes in their courses (see section 4.3), we do not expect that asking a more direct question about JEDI would have yielded many JEDI-positive responses.

For most teachers, ERT meant doing what little they could as quickly as possible. A proactive mentality toward accessibility and JEDI did not seem to be part of the courses reported on 
by teachers who responded to this survey before the pandemic, and accessibility considerations in the transition to ERT were often made only when learners required accommodations.

This may, in part, stem from a general lack of infrastructure for facilitating the transition to ERT. For example, many instructors responding to our survey did not know that they could easily generate subtitles for new videos - important for deaf and hearing-impaired learners but desired by many non-hearing-impaired learners - by uploading the videos to YouTube. More infrastructure at institutions and among teachers in our field could help instructors be more proactive about JEDI so that it does not get overlooked in either emergency or non-emergency teaching.

6.2.2. SHARED RESOURCES. Overwhelmingly, teachers who responded to our survey reported that they would appreciate a curated repository of pre-made teaching materials, particularly content for their classes like videos and problem sets, but also tools for teaching remotely like online tree drawing utilities. Developing such a repository is a major challenge for the field of Linguistics: our field has a massive scope (as the responses from this survey indicate, see section 2.2) and a single central collection of resources is unlikely to fulfill the needs of all linguists. Movement in this direction picked up steam during the pandemic, notably by the Online Teaching Linguistics Facebook group and by the LSA's Faculty Learning Community on the Scholarship of Teaching and Learning for Linguists, which has published a webpage with a curated collection of resources shared by linguists (LSA FLC, 2020; see the reference for a link to the resource). Beyond the independent resources listed, the webpage provides guidance to help Linguistics instructors teach with more of an eye toward accessibility and equitability. We recommend that when teachers save time by using these resources instead of developing their own, they use the time saved to consider whether their pedagogical choices are just, equitable, diverse, and inclusive.

7. Conclusion. Ultimately, this survey (and, more broadly, the experience of ERT during the COVID-19 pandemic) has shed light on creativity, flexibility, and resilience in the linguistics community, as well as on areas, such as JEDI, on which we can focus our attention for future growth.

\section{References}

Bergmann, Jonathan, \& Aaron Sams. 2012. Flip your classroom: Reach every student in every class every day. International Society for Technology in Education.

Chirikov, Igor, Krista. M Soria, Bonnie Horgos \& Daniel Jones-White. 2020. Undergraduate and graduate students' mental health during the COVID-19 pandemic. UC Berkeley: Center for Studies in Higher Education. https://escholarship.org/uc/item/80k5d5hw.

Cuschieri, Sarah \& Jean Calleja Agius. 2020. Spotlight on the shift to remote anatomical teaching during Covid-19 pandemic: Perspectives and experiences from the University of Malta. Anatomical Sciences Education 13(6). 671-679. https://doi.org/10.1002/ase.2020.

Czerniewicz, Laura, Najma Agherdien, Johan Badenhorst, Dina Belluigi, Tracey Chambers, Muntuwenkosi Chili, Magriet de Villiers, Alan Felix, Daniela Gachago, Craig Gokhale, Eunice Ivala, Neil Kramm, Matete Madiba, Gitanjali Mistri, Emmanuel Mgqwashu, Nicola Pallitt, Paul Prinsloo, Kelly Solomon, Sonja Strydom, Mike Swanepoe, Faiq Waghid \& Gerrit Wissing. 2020. A wake-up call: Equity, inequality, and Covid-19 emergency remote teaching and learning. Postdigital Science and Education 2. 946-967. https://doi.org/10.1007/s42438-020-00187-4. 
de Souza, Gustavo Henrique Silva, Wallas Siqueira Jardim, Geraldo Lopes Junior, Yuri Bento Marques, Nilton Cesar Lima, Rômulo Silviera Ramos. 2020. Brazilian students' expectations regarding distance learning and remote classes during the COVID-19 pandemic. Educational Sciences: Theory \& Practice 20(4). 65-80. https://doi.org/10.12738/jestp.2020.4.005.

García-Peñalvo, Francisco José, Ricardo Rivero-Ortega Rector, María José Rodríguez-Conde \& Nicolás Rodríguez-García. 2020. The institutional decisions to support remote learning and teaching during the COVID-19 pandemic. 2020 X International Conference on Virtual Campus (JICV). 1-5. https://doi.org/10.1109/JICV51605.2020.9375683.

Gillis, Alanna, \& Laura M. Krull. 2020. COVID-19 remote learning transition in Spring 2020: Class structures, student perceptions, and inequality in college courses. Teaching Sociology 48(4). 283-299. https://doi.org/10.1177/0092055X20954263.

Hodges, Charles, Stephanie Moore, Barb Lockee, Torrey Trust \& Aaron Bond. 2020. The difference between emergency remote teaching and online learning. Educause Review. [Web page]. https://er.educause.edu/articles/2020/3/the-difference-between-emergency-remoteteaching-and-online-learning.

Huang, Min, Yahui Shi \& Xiaoqiong Yang. 2021. Emergency remote teaching of English as a foreign language during COVID-19: Perspectives from a university in China. International Journal of Educational Research and Innovation 15. 400-418. https://doi.org/10.46661/ijeri.5351.

Jelińska, Magdalena \& Michał B. Paradowski. 2021. Teachers' engagement in and coping with emergency remote instruction after COVID-19-induced school closures: A multinational contextual perspective. Online Learning Journal 25(1). 303-328. https://doi.org/10.24059/olj.v25i1.2492.

Karakaya, Kadir. 2021. Design considerations in emergency remote teaching during the COVID19 pandemic: A human-centered approach. Education Technology Research and Development 69. 295-299. https://doi.org/10.1007/s11423-020-09884-0.

Linguistic Society of America Faculty Learning Community on the Scholarship of Teaching and Learning for Linguists. 2020. Scholarly teaching in linguistics. [Web page]. https://tinyurl.com/ScholarlyTeachingInLinguistics.

Milman, Natalie B. 2020, March 30. This is emergency remote teaching, not just online teaching. Education Week. [Web page]. https://www.edweek.org/leadership/opinion-this-is-emergency-remote-teaching-not-just-online-teaching/2020/03.

Moorehouse, Benjamin Luke \& Lucas Kohnke 2021. Thriving or surviving emergency remote teaching necessitated by COVID-19: University teachers' perspectives. The Asia-Pacific Education Researcher 30. 279-287. https://doi.org/10.1007/s40299-021-00567-9.

Osman, Mohamed ElTahir. 2020. Global impact of COVID-19 on education systems: the emergency remote teaching at Sultan Qaboos University. Journal of Education for Teaching 46(4). 463-471. https://doi.org/10.1080/02607476.2020.1802583.

Rosenthal, Anton. 2005. Re-envisioning teaching graduate seminars. [Web page]. Center for Teaching Excellence, The University of Kentucky. https://cte.ku.edu/portfolios/rosenthal2005.

Rotas, Erwin E. \& Michale B. Cahapay. 2020. Difficulties in remote learning: Voices of Philippine University students in the wake of COVID-19 crisis. Asian Journal of Distance Education 15(2). 147-158. https://doi.org/10.5281/zenodo.4299835. 
Saldaña, Johnny. 2016. The coding manual for qualitative researchers. Thousand Oaks, CA: Sage Publications.

Shim, Tae Eun \& Song Yi Lee. 2020. College students' experience of emergency remote teaching due to COVID-19. Children and Youth Services Review 119. 105578. https://doi.org/10.1016/j.childyouth.2020.105578.

Smith, Erika K. \& Ece Kaya. 2021. Online university teaching at the time of COVID-19 (2020): An Australian perspective. International Academic Forum Journal of Education 9(2). 183200. https://doi.org/10.22492/ije.9.2.11.

Soria, Krista M. \& Bonnie Horgos. 2020. Social class differences in students' experiences during the COVID-19 pandemic. UC Berkeley: Center for Studies in Higher Education. https://escholarship.org/uc/item/3hw2m00g.

Tomlinson, Carol Ann, \& Jay McTighe. 2006. Integrating differentiated instruction \& understanding by design: Connecting content and kids. Alexandria, VA: Association for Supervision and Curriculum Development.

Wise, Alyssa \& Yoav Bergner. 2020. College in the time of Corona: Spring 2020 student survey. New York, NY: NYU-LEARN. https://steinhardt.nyu.edu/learn/research-and-applications/reports.

Zuraw, Kie, Ann M. Aly, Isabelle Lin \& Adam J. Royer. 2019. Gotta catch'em all: Skills grading in undergraduate linguistics. Language 95(4). 406-427.

https://doi.org/10.1353/lan.2019.008. 